\title{
Evaluation Index System Construction for Geological Environmental Bearing Capacity and Its Application in Henan Province, China
}

\author{
He Ziguang*†, Zhang Yujiao*, Huang Lei**, Duan Zhao*** and Lin Jianhao* \\ *Institute of Architecture Engineering, Huanghuai University, Zhumadian 463000, China \\ **Water Conservancy and Civil Engineering College, Inner Mongolia Agricultural University, Hohhot 010018, China \\ ***College of Geology and Environment, Xi' an University of Science and Technology, Xi' an 710054, China \\ †Corresponding author: He Ziguang; hzg198762@163.com
}

Nat. Env. \& Poll. Tech Website: www.neptjournal.com

Received: 06-05-2020

Revised: 25-06-2020

Accepted: 18-07-2020

\section{Key Words:}

Geological environmental bearing capacity

Evaluation index system Socioeconomic activities Henan Province

\begin{abstract}
Geological environment is a resource base, environmental base, and engineering base for human socioeconomic activities. The main function of the geological environment is to provide stable and safe living space and essential resources for the existence and development of human society. However, geological environmental problems become increasingly prominent in some provinces in China due to fragility of the geological environment, uneven population distribution, backward economic development, and massive construction projects. The function of geological environments in some provinces to support sustainable economic and social development is evidently insufficient, and the threshold values of their geological environmental bearing capacity nearly reach the upper limit. For example, Henan Province, China, an evaluation index system for geological environmental bearing capacity, was established from three aspects, as follows: natural hazard, geological disaster, and disaster control. The weights of evaluation indexes were calculated using the variation coefficient method. Finally, the geological environmental bearing capacity of Henan Province during 2010-2018 was measured through the comprehensive evaluation method. Results showed that the constructed evaluation index system for geological environmental bearing capacity, which consisted of 34 indexes, was scientific and reasonable. During 2010-2018, the geological environmental bearing capacity of Henan Province was superior or excellent. Geological environmental bearing capacity can be improved by reinforcing the construction of legal rules and laws for geological environmental protection, carrying out research work regarding geological environmental bearing capacity, launching geological environmental monitoring and early warning system construction, and implementing feasibility demonstration for the geological environment of major construction projects. The study results can provide practical guidance and reference to realize the predictive analysis of geological environmental bearing capacity and coordinate human socioeconomic activities and geological environment.
\end{abstract}

\section{INTRODUCTION}

Geological environment refers to the surface space of lithosphere, which interacts with hydrosphere, atmosphere, and biosphere and is closely related to human activities. It is also a material base and prerequisite for sustainable social development of human beings. Human activities are also based on the natural environment, most of which are closely associated with the geological environment. Geological environmental bearing capacity is the maximum ability of the geological environment to bear the influences and changes brought by human activities. It is an important environmental constituent part in studies on resource environmental bearing capacity. As an important factor used to measure sustainable human development, it can reflect the coordination degree between human activities and geological environmental system. Effective resource distribution and utilization, efficient utilization of land resources, and preventive treatment of geological environment are urgent problems faced by China in the eco-environmental construction and new-type urbanization process under the major background of capacity utilization reform, supply-side structural adjustment, and socioeconomic updating and upgrading. Especially because of enormous environmental pollution, various geological environmental problems emerge, such as surface subsidence, sand liquefaction, soil salinization, water and soil corrosion, and a partially high degree of mineralization of shallow underground water. Scientific understanding and handling of these geological environmental problems are greatly important to infrastructure construction and resource development and utilization.

Featured by complicated natural geological conditions and fragile ecological environment, Henan Province in China is distributed with special unfavourable geological environmental conditions and severe geological disasters. Moreover, numerous geological environmental problems 
are triggered by human activities in Henan Province. Special unfavourable geological environmental conditions mainly include special unfavourable rock and earth mass (collapsible loess and swell-shrinking soil), primary geochemical anomaly (high fluorine water, low iodine water, and saline water), and secondary geochemical anomaly (soil salinization). Geological disasters include collapse, landslide, debris flow, water and soil loss, surface collapse, water inrush of the pit, and gas explosion. Geological environmental problems include exhaustion of water resources, water contamination, and stacking of solid wastes. These factors have become important in restricting the improvement of people's living standards and socioeconomic development in Henan Province. Regional environmental features in Henan Province indicate that its economic development is mainly restricted by geological environmental problems. Thus, studying the geological environmental bearing capacity for economic activities in this region is especially important. Therefore, on the research basis of regional geological environmental background in Henan Province, investigating the influence factors of the regional geological environment on economic activities and evaluating its geological environmental bearing capacity have great theoretical and realistic significance for regulating socioeconomic activities and realizing coordinated development between geological environment and social economy.

\section{PAST STUDIES}

Geological environmental bearing capacity is the extension of the environmental bearing capacity theory. It lays particular emphasis on sustainable development and protection of the geological environment. Geological environment is the environmental base for human society. With the emergence of numerous environmental problems and elevated requirements for geological environmental development and protection, studies on the geological environment have gradually developed, initially from susceptibility and danger grading of geological disasters and then to geological environmental quality evaluation until the present studies on geological environmental bearing capacity. Rees (1992) proposed ecological footprint method to evaluate geological environmental bearing capacity by comparing ecological footprints at supply level and ecological bearing capacity at demand level for geological environmental bearing capacity. Fuchu et al. (1994) investigated topography, geology, soil types, and properties and their distribution range in Tongchuan City, as well as main geotechnical engineering and geological environmental problems induced by human engineering activities. Lew (2001) evaluated some developable areas in California, and the results showed that the existence of active earthquake fault, young loose alluvial deposit, and shallow groundwater was a factor possibly resulting in geological liquefaction in many areas in California. Youquan (2004) analyzed water resource bearing capacity of Wei River basin based on the introduced water resource distribution features of Gansu segment of Wei River basin as well as the existing effective output and bearing capacity. The results showed that the optimal bearing capacity of water resources in this area was 3,550,000 people. Wackernagel et al. (2004) deemed that the damage of rock slope on the Himalayas was a common feature and proposed concrete measures of improving rock stability on the Himalayas. Dill et al. (2005) built a lithofacies relief model for African savannah in the south of Malawi, acquired the evaluation results of rock bearing capacity, and put forward measures of reinforcing geological disaster prediction. Chuan-Ming et al. (2007) expounded the concept of geological environmental bearing capacity, highlighted the geological environmental bearing capacity features based on sustainable development and environmental bearing capacity, and introduced the evaluation process of geological environmental bearing capacity. Chang-Fei et al. (2011) combined actual pile foundation of the marine drilling platform, considering geological drilling of Shuangtaizi estuary engineering, to analyze and discuss the bearing capacity characteristics of mucky strata at Shuangtaizi estuary. Wagner et al. (2013) deemed that the increasing urbanization and construction of high-rise buildings in Meshed of Iran affected the geological environmental bearing capacity. They used sequential indicator simulation and sequential Gaussian simulation methods to establish a 3D geological engineering model for standard penetration test results of Meshed sedimentary deposits. The results showed that civil engineering causes fierce change to the geological environment of Meshed sedimentary basin. Qi-Shan et al. (2015) believed that the geological environmental bearing capacity was poor in covered karst area, and the groundwater development and utilization led to karst collapse. Then, they proposed measures of improving geological environmental bearing capacity in karst areas. Jiang-Ping et al. (2015) explored into soil layer stability and bearing capacity in this area with geophysical interpretation data of offshore areas in the North Sea in Guangxi Province. The results showed that this area is a complicated and diversified marine engineering geological environment, and the overall stability of clayey soil was evaluated. Wang et al. (2017) studied geological environmental bearing capacity in Guizhou karst area, used AHP to perform a numerical simulation of limestone solubility in different areas in Guizhou, and constructed a quantitative method combining these factors. Existing studies have shown to lay particular emphasis on 
quantitative evaluation of bearing capacity. The study areas vary in natural, social, and economic conditions, evaluation factors are diverse, and different evaluation methods are applied among studies on bearing capacity. Thus, no mature, complete, and acknowledged research system has been formed in the quantitative measurement process, few studies have involved spatial distribution pattern of regional bearing capacity and identifying the associations among quality, scale, and spatial distribution of bearing capacity is difficult. Geological environmental bearing capacity and its quantitative research are keys to accurately and quantitatively master regional geological environmental bearing capacity. Theoretical studies on bearing capacity have contributed to comprehensive and in-depth studies on bearing capacity. The introduction and development of various mathematical models have greatly improved quantitative level and accuracy of bearing capacity studies. The bearing capacity research methods have developed from single-index static analysis into multiobjective, dynamic, and comprehensive system analysis. Therefore, in Henan Province, China, for example, the changing trend of geological environmental bearing capacity was analyzed from time dimension by comprehensively combing index systems of geological environmental bearing capacity established in the existing studies to enrich the connotations of geological environmental bearing capacity and propose reference suggestions for adjustment of geological environmental bearing capacity.

\section{MODEL PROFILE AND INDEX SYSTEM}

\section{Model Profile}

(1) Dimensionless processing of indexes: Evaluation indexes vary in dimension; thus, if they are directly calculated, then the results are impacted. Therefore, performing dimensionless processing of the evaluation indexes is necessary. Positive indexes are processed in formula (1), as follows:

$$
Y_{i j}=\frac{X_{i j}-X_{\text {m in }}}{X_{i \mathrm{max}}-X_{i \text { m }}}
$$

For negative indexes, the processing method in formula (2) is used, as follows:

$$
Y_{i j}=\frac{X_{i \max }-X_{i j}}{X_{i \max }-X_{i \min }}
$$

In formulas (1) and (2), $Y_{i j}$ denotes the value of the $j^{\text {th }}$ evaluation index of class $i$ after standardization; $X_{i j}$ represents the actual value of the $j^{\text {th }}$ evaluation index of class $i$; $X_{i \max }$ is the maximum value of evaluation indexes of class $i ; X_{i \min }$ is the minimum value of evaluation indexes of class $i$.

(2) Variation coefficient method: Variation coefficient method is used to calculate the weight of each evaluation index. As an objective calculation method, the variation coefficient method can avoid the influence brought by subjective factors. This method can directly use the information contained in the indexes and calculate their weights. The calculation process is as follows. First, the mean value and standard deviation of each index are calculated in formulas (3) and (4), as follows:

$$
\begin{gathered}
\overline{X_{i}}=\frac{1}{n} \sum_{j=1}^{n} X_{i j} \\
S_{i}=\sqrt{\frac{1}{n-1} \sum_{j=1}^{n}\left(X_{i j}-\overline{X_{i}}\right)^{2}}
\end{gathered}
$$

Then, the variation coefficient is calculated in formula (5), as follows:

$$
Z_{i}=\frac{S_{i}}{\overline{X_{i}}}
$$

The weight of each index is calculated in formula (6), as follows:

$$
\mathrm{W}_{i}=\frac{Z_{i}}{\sum_{i=1}^{n} Z_{i}}
$$

In formulas (3)-(6), $i$ is the class of evaluation index; $j$ is the concrete index under each class of evaluation index. The present foreign evaluation methods of geological environmental bearing capacity mainly include ecological footprint method, state-space method, and comprehensive evaluation method. A comprehensive evaluation model is established on the basis of the comprehensive evaluation method. This method, which is also called multivariable comprehensive evaluation method, uses multiple indexes to evaluate multiple objects participating in the evaluation. The comprehensive evaluation model is feasible and effective with the advantages of strong pertinence, comprehensive analysis contents, easy data acquisition, convenient calculation, and comprehensible evaluation results. It can realize accurate evaluation of geological environmental bearing capacity, which is complex, fuzzy, and variable. The comprehensive evaluation model can be expressed using formula (7), as follows:

$$
P=\sum_{i=1}^{n} Y_{i} \bullet W_{i}
$$

In formula (7), $P$ is the geological environmental bearing capacity of the evaluation object; $Y_{i}$ is the value of the $i$ (th) evaluation index of the evaluation object after nondimensionalization; $W_{i}$ is the weight of the $i^{\text {th }}$ evaluation index of the evaluation object. The classification standard proposed in most studies on geological environmental bearing capacity is divided into four grades, namely, superior, good, medium, and poor using interval method, and the grading standard is given in Table 1. 


\section{Index System}

Geological environmental bearing capacity is a description of the regional man-land systematic relationship. Thus, indexes are selected mainly from two aspects, namely, "land" and "man." "Land" mainly contains resource subsystem, environmental subsystem, and regulating subsystem; "man" usually includes subsystems, such as population, society, and economy. Variables directly related to the geological environment are mainly considered in the selection of concrete indexes. In addition, indexes, which are incorporated and organized or could be acquired through simple calculation, are selected from national, local, and industrial statistical data. Then, attention is focused on the coordination with the statistical method and various standards in industries such as geology and environmental protection. The established index system for geological environmental bearing capacity in Henan Province is given in Table 2. The investigation period is 2010-2018, and data are derived from the China National Statistical Database.

\section{RESULT ANALYSIS}

The collected data are calculated according to the above formula, and the standard deviation, mean value, and variation coefficient of all indexes are calculated, as given in Table 3 .
According to formula (7), the geological environmental bearing capacities of Henan Province during 2010-2018 are calculated, as shown in Fig. 1.

Fig. 1 shows that during 2010-2018, the geological environmental bearing capacity in Henan Province is superior or excellent in most of the times. Henan Province is a flat terrain with few faults and geological disasters and good engineering geological conditions. Moreover, it is a developed industry and commerce with convenient transportation and complete infrastructure. However, human engineering activities in Henan Province include dispersive small-scale mining in addition to farming activities in recent years. The quantity of geological disasters is large, but the scale is small. Abundant geological tourism resources are available, but the degree of development and utilization is relatively low; the vegetation cover index is large. Henan Province shall take the lead in establishing exit and access system to measure and evaluate standards following the influence of engineering projects on the geological environment. Meanwhile, depending on various advantages in abundant geological relics, folk custom, and other tourism resources, Henan Province should cultivate and strengthen its green industries, such as tourism, culture, and characteristic agricultural products. Especially in 2011, the geological environmental bearing capacity was only 0.36 in Henan Province, fully indicating that geological

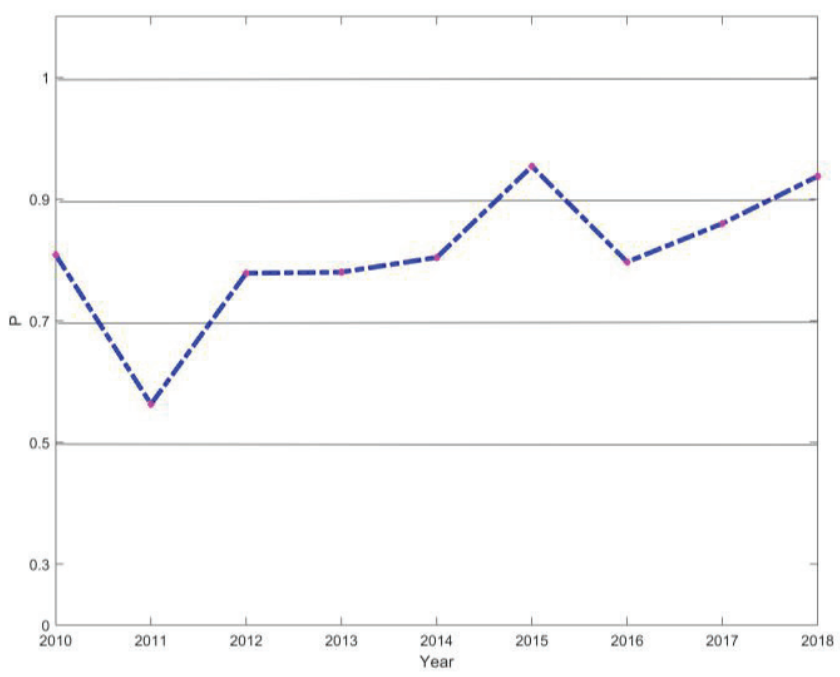

Fig. 1: Geological environmental bearing capacities of Henan Province during 2010-2018.

Table 1: Grading standard of geological environmental bearing capacity.

\begin{tabular}{|lllll|}
\hline State & Superior & Good & Medium & Poor \\
\hline Grading interval & $\geq 0.9$ & $(0.7,0.9)$ & $(0.5,0.7)$ & $(0,0.5)$ \\
\hline
\end{tabular}


Table 2: Index system of geological environmental bearing capacity.

\begin{tabular}{|c|c|c|}
\hline First-level index & Second-level index & Unit \\
\hline \multirow{12}{*}{ Natural disaster } & Crop damage area & One thousand hectares \\
\hline & Crop failure area & One thousand hectares \\
\hline & Drought-stricken area & One thousand hectares \\
\hline & Drought-induced crop failure area & One thousand hectares \\
\hline & Flood, landslide, debris flow, and typhoon-stricken area & One thousand hectares \\
\hline & Flood, landslide, debris flow, and typhoon-induced crop failure area & One thousand hectares \\
\hline & Hailstorm-stricken area & One thousand hectares \\
\hline & Hailstorm-induced crop failure area & One thousand hectares \\
\hline & Natural disaster-hit population & Ten thousand people \\
\hline & Natural disaster-induced death population & People \\
\hline & Direct economic loss of natural disaster & One hundred million yuan \\
\hline & Number of geological disasters & Number of times \\
\hline \multirow{6}{*}{ Geological disaster } & Number of landslide disasters & Number of times \\
\hline & Number of collapse disasters & Number of times \\
\hline & Number of debris flow disasters & Number of times \\
\hline & Number of surface subsidence disasters & Number of times \\
\hline & Geological disaster-induced direct economic loss & 10 thousand yuan \\
\hline & Number of geological disaster prevention and control projects & $\mathrm{Ea}$ \\
\hline \multirow{16}{*}{ Disaster control } & Investments on geological disaster prevention and control & 10 thousand yuan \\
\hline & Total afforestation area & One thousand hectares \\
\hline & Artificial afforestation area in the year & One thousand hectares \\
\hline & Hillsides closed to facilitate afforestation on nonforest land and open-forest land & One thousand hectares \\
\hline & Land use area in forestry & 10 thousand hectares \\
\hline & Forest area & 10 thousand hectares \\
\hline & Man-made forest area & 10 thousand hectares \\
\hline & Forest coverage rate & $\%$ \\
\hline & Total standing forest stock & One hundred million cubic meters \\
\hline & Forest growing stock & One hundred million cubic meters \\
\hline & Investments completed for industrial pollution control & 10 thousand yuan \\
\hline & Investments completed for wastewater management projects & 10 thousand yuan \\
\hline & Investments completed for waste gas management projects & 10 thousand yuan \\
\hline & Investments completed for solid waste management projects & 10 thousand yuan \\
\hline & Investments completed for noise control projects & 10 thousand yuan \\
\hline & Investments completed for other governance projects & 10 thousand yuan \\
\hline
\end{tabular}

environmental protection started late in Henan Province with inefficient measures, insufficient funds, dispersive management, and low consciousness, which were the primary causes for the weak foundation. Moreover, many departments are involved in geological environmental protection problems, along with common problems of barriers between high and low levels; each department attends to its own duties and disunity. With insufficient funds, implementing exploration and governance of geological disasters is difficult. Villages cannot realize required relocation, and consequently, some people are stricken in the threats imposed by geological disasters. The geological disaster information system in 
Table 3: Standard deviation, mean value, and variation coefficient of indexes.

\begin{tabular}{|c|c|c|c|c|}
\hline Index & Unit & $\begin{array}{l}\text { Standard } \\
\text { Deviation }\end{array}$ & $\begin{array}{l}\text { Mean } \\
\text { value }\end{array}$ & $\begin{array}{l}\text { Variation } \\
\text { Coefficient }\end{array}$ \\
\hline Crop damage area & One thousand hectares & 519.77 & 1119.85 & 0.46 \\
\hline Crop failure area & One thousand hectares & 60.49 & 78.07 & 0.77 \\
\hline Drought-stricken area & One thousand hectares & 636.13 & 640.28 & 0.99 \\
\hline Drought-induced crop failure area & One thousand hectares & 72.08 & 53.36 & 1.35 \\
\hline Flood, landslide, debris flow, and typhoon-stricken area & One thousand hectares & 418.51 & 433.52 & 0.97 \\
\hline Flood, landslide, debris flow, and typhoon-induced crop failure area & One thousand hectares & 29.96 & 30.41 & 0.99 \\
\hline Hailstorm-stricken area & One thousand hectares & 56.58 & 104.43 & 0.54 \\
\hline Hailstorm-induced crop failure area & One thousand hectares & 6.22 & 6.71 & 0.93 \\
\hline Natural disaster-hit population & 10 thousand people & 770.06 & 1549.23 & 0.50 \\
\hline Natural disaster-induced death population & People & 43.41 & 37.14 & 1.17 \\
\hline Direct economic loss of natural disaster & One hundred million yuan & 52.53 & 85.51 & 0.61 \\
\hline Number of geological disasters & Number of times & 182.79 & 106.18 & 1.72 \\
\hline Number of landslide disasters & Number of times & 168.95 & 77.89 & 2.17 \\
\hline Number of collapse disasters & Number of times & 9.84 & 8.65 & 1.14 \\
\hline Number of debris flow disasters & Number of times & 5.62 & 3.36 & 1.67 \\
\hline Number of surface subsidence disasters & Number of times & 7.94 & 17.59 & 0.45 \\
\hline Geological disaster-induced direct economic loss & 10 thousand yuan & 5315.15 & 3550.01 & 1.50 \\
\hline Number of geological disaster prevention and control projects & $\mathrm{Ea}$ & 20.04 & 15.40 & 1.30 \\
\hline Investments on geological disaster prevention and control & 10 thousand yuan & 3996.30 & 4858.23 & 0.82 \\
\hline Total afforestation area & One thousand hectares & 38.32 & 197.03 & 0.19 \\
\hline Artificial afforestation area in the year & One thousand hectares & 39.05 & 153.58 & 0.25 \\
\hline $\begin{array}{l}\text { Hillsides closed to facilitate afforestation on non-forest land and } \\
\text { open-forest land }\end{array}$ & One thousand hectares & 14.33 & 32.49 & 0.44 \\
\hline Land use area in forestry & 10 thousand hectares & 5.25 & 456.58 & 0.01 \\
\hline Forest area & 10 thousand hectares & 14.70 & 329.04 & 0.04 \\
\hline Man-made forest area & 10 thousand hectares & 6.22 & 206.90 & 0.03 \\
\hline Forest coverage rate & $\%$ & 0.87 & 19.70 & 0.04 \\
\hline Total standing forest stock & One hundred million cubic meters & 0.12 & 2.11 & 0.06 \\
\hline Forest growing stock & One hundred million cubic meters & 0.12 & 1.59 & 0.08 \\
\hline Investments completed for industrial pollution control & 10 thousand yuan & 197849.23 & 331983.82 & 0.60 \\
\hline Investments completed for wastewater management projects & 10 thousand yuan & 17432.72 & 40201.27 & 0.43 \\
\hline Investments completed for waste gas management projects & 10 thousand yuan & 178454.04 & 242109.90 & 0.74 \\
\hline Investments completed for solid waste management projects & 10 thousand yuan & 6813.72 & 5471.57 & 1.25 \\
\hline Investments completed for noise control projects & 10 thousand yuan & 347.17 & 395.22 & 0.88 \\
\hline Investments completed for other governance projects & 10 thousand yuan & 64781.49 & 50803.85 & 1.28 \\
\hline
\end{tabular}

the entire Henan Province has not been established. Thus, sharing of geological disaster information resources between relevant departments to provide information services for government decision and the public is difficult to realize. Geological disasters in Henan Province have a wide range and high strength. Various hidden dangers, such as the easy and extensive occurrence of geological disasters, exist in its economic pattern and geological environment. Prevention and control measures are far from containing the deteriorated spreading situation of geological disasters, and the preven- 
tion and governance works still catch interests of multiple aspects. Therefore, a number of complicated works remain to be completed, namely, construction of guarantee system, elimination of threats from numerous points with hidden hazards, and implementation of prevention scheme.

\section{POLICY RECOMMENDATIONS}

Construction of Legal Rules and Laws for Reinforcing Geological Environmental Protection

Henan Regulations on Geological Environmental Protection have played an important role in protecting the Henan geological environment since it was enacted and implemented in 2012. During the implementation process, relevant departments bear clear responsibilities and duties, exert concerted efforts, strictly enforce laws, and strengthen supervision, effectively promoting the comprehensive and in-depth implementation of geological environmental protection. However, concrete scale in the implementation process is limited. To further conduct geological environmental protection work, Henan Province should launch related legislation and investigation works, further define and standardize administration authority and law enforcement status of the Ministry of Land and Resources in the aspect of geological environmental protection, and clarify responsibilities and obligations of different departments. Geological environmental protection should have laws to abide by and standards to quote with clear rights and liabilities and concrete scale.

\section{Carry Out Investigation Work on Geological Environmental Bearing Capacity}

In accordance with relevant research results on land bearing capacity, environmental bearing capacity, and resource bearing capacity during the urbanization progress, Henan Province should formulate unified technical standard and establish a scientific and effective research system for geological environmental bearing capacity. The investigation, appraisal, and zoning works should be implemented for geological environmental bearing capacity under different measuring scales within the entire Henan Province. A clear picture of the current status of geological environmental bearing capacity in Henan Province should be obtained, and the main factors influencing and restricting geological environmental bearing capacity should be determined. Key areas to carry out monitoring and early warning demonstration work for geological environmental bearing capacity should be selected, and technical support should be provided to the government to reasonably guide industrial distribution and population mobility. Research work on restoration technology of geological environmental bearing capacity should be reinforced, restoration studies on all types of impacted and destructed geological environments should be conducted, destructed or saturated bearing capacity should be restored as much as possible, and local socioeconomic development and ecological civilization construction should be performed.

\section{Construction of Geological Environmental Monitoring and Early Warning System}

At present, the basic means of geological environmental investigation is the traditional field geological investigation. This approach lacks remote and real-time early modernized and automated warning and monitoring networks with small monitoring scope and backward means and technologies. It fails to provide dynamic real-time early warning information for the prevention and control of geological environmental problems, and it cannot easily prevent the occurrence of geological environmental problems. An ideal approach is suggested to launch geological environmental monitoring and early warning system construction as soon as possible, conduct long-term monitoring of main geological environmental problems of mines, hidden danger points of geological disasters, groundwater level, and groundwater pollution, master change process, and predict future development direction to provide a scientific basis for sustainable socioeconomic development.

\section{Implement Geological Environmental Feasibility Demonstration for Major Construction Projects}

With the view of long-term efficiency of geological environmental protection, Henan Province should conduct geological environmental feasibility demonstration for major construction projects and limit human engineering activities within bearable scope. It should focus on supervision and monitoring of construction projects exerting major influences on the geological environment. It should comb and analyze major projects to protect the geological environment, list the directories, perform irregular supervision and inspection, and urge responsible units to practice geological environmental protection. It should synchronously carry out suitability research on geological environmental bearing capacity during the urbanization progress. Henan Province should carry out urban geological environmental quality evaluation and studies on urban geological environmental bearing capacity in full consideration of natural and social properties of cities and towns. Regions suitable for urban development, their development scale, and their development level should be analyzed from the aspect of the geological environment. Also, countermeasures for improving urban geological environmental bearing capacity should be proposed to provide a scientific basis for urban territorial planning and management. 


\section{CONCLUSION}

With continuous enhancement of human activities and elevation of the scale, strength, and speed of geological environmental development, utilization, and transformation, geological environments in many provinces in China face unprecedented pressure. To effectively control or adjust human activities to adapt to geological environmental conditions and reasonably develop and utilize the geological environment, we must determine current geological environmental bearing capacities in different provinces. In Henan Province, China, for example, the evaluation index system of geological environmental bearing capacity was established, the variation coefficient method was used to calculate the weight of each evaluation index, and the geological environmental bearing capacities of Henan Province during 2010-2018 were calculated through the comprehensive evaluation method. The results showed that during 2010-2018, the geological environmental bearing capacity of Henan Province was superior or excellent. The proposed measures to improve geological environmental bearing capacity include strengthening the implementation of legal rules and laws for geological environmental protection, carrying out investigation works of geological environmental bearing capacity, launching geological environmental monitoring and early warning system construction, and implementing geological environmental feasibility demonstration for major construction projects. An in-depth study is suggested to form systematic and scientific theories and evaluation technology system for resource environmental bearing capacity, establish bearing capacity evaluation model by combining practical situations of different regions, and probe into diversity of territorial resource diversity and fragility of ecological geological environment.

\section{ACKNOWLEDGMENT}

This study was supported by Henan Science and Technology Research Planning Project (NO.182102310773); Key Research Projects of Universities in Henan Province (NO.19A410002); National Natural Science Foundation of China (NO.51969023, No.41702298), High-level Talents Research Start-up Fund Project of Inner Mongolia Agricultural University (NO.NDYB2018-60), Inner Mongolia Autonomous Region Science and Technology Plan Project
(NO.2019GG141), Inner Mongolia Autonomous Region Natural Science Foundation of China (NO.2018MS05005) and Inner Mongolia Autonomous Region Higher Education Science Research Project of China (NO.NJZY18064).

\section{REFERENCES}

Chang-Fei, T., Fa-Qing, Q. I., Yan-Ping, L., Chun-yu, J.U., Wei, Q.U., Bingdu A.N. and Fang-qi Wang 2011. Bearing capacity of neritic facies silt from Shuangtaizi river estuary. Coastal Engineering, 30(2): 38-42.

Chuan-Ming, M.A. and Yi-Hui, M.A. 2007. Tentative Investigation of Bearing Capacity of Geological Environment for Sustainable Development. Environmental Science \& Technology, 30(8): 64-73.

Dill, H.G., Ludwig, R.R., Kathewera, A. and Mwenelupembe, J. 2005. A lithofacies terrain model for the Blantyre Region: Implications for the interpretation of Palaeosavanna depositional systems and for environmental geology and economic geology in southern Malawi. Journal of African Earth Sciences, 41(5): 341-393.

Fuchu, D., Yuhai, L. and Sijing, W. 1994. Urban geology: A case study of Tongchuan city, Shaanxi Province, China. Engineering Geology, 38(1-2): 165-175.

Jiang-Ping, Y., Yao-Hong, S., Ning-Feng, Z., Sheng-Zhong, M. and Taihao, C. 2015. Analysis of engineering geological characteristics and specific problems of the offshore area in Beihai, Guangxi. Journal of Geology, 39(4): 633-640.

Lew, M. 2001. Liquefaction evaluation guidelines for practicing engineering and geological professionals and regulators. Environmental \& Engineering Geoscience, 7(4): 301-320.

Qi-Shan, D., Zhen-Dong, C., Fan-Tao, M. and Xiao-Qing, S. 2015. Analysis of causes of karst collapse and the corresponding countermeasures during the running of ground source heat pump in the covered karst areas. Groundwater, 37(5): 11-13.

Sastry, R.G.S. and Viladkar, M.N. 2004. Role of integrated geophysical studies in defining the rock profile below steep hill slope at the base of an endangered multi-storeyed building in Himachal Pradesh. Journal of the Geological Society of India, 63(3): 282-290.

Rees, W. E. 1992. Ecological footprints and appropriated carrying capacity: What urban economics leaves out. Environment \& Urbanization, 4(2): 121-130.

Wagner, Marian 2013. The geological aspects of meta-lignite and sub-bituminous coal occurrences in Poland within the context of deposits and uneconomic occurrences in Europe. Gospodarka Surowcami Mineralnymi - Mineral Resources Management, 29(4): 25-45.

Wackernagel, M., Monfreda, C., Schulz, N. B., Erb K., Haberl, H. and Krausmann, F. 2004. Calculating national and global ecological footprint time series: resolving conceptual challenges. Land Use Policy, 21(3): 271-278.

Youquan, W. 2004. Analysis on the bearing capacity of water resources in Gansu reaches of Weihe river valley. Groundwater, 26(2)137-139.

Wang, Z.M., Yang, G.L., Yang, R.D., Rawal, K. and Hu, L.B. 2017. Evaluating the factors influencing limestone-dissolution characteristics in the karst regions of Guizhou, China. Journal of Testing and Evaluation, 45(1): 220-229. 